\title{
The Ability of Databases and Guidelines to Drive Quality Improvement
}

\author{
Michael E. McCormick • Rahul K. Shah
}

Published online: 17 December 2013

(c) Springer Science+Business Media New York 2013

\begin{abstract}
The increased attention on excessive healthcare spending and the need to improve the efficiency and quality of healthcare in the USA has prompted medical specialties such as otolaryngology to take the lead in quality improvement initiatives. These projects aim to reduce variation in certain health practices, improve patient outcomes, and stimulate further strides toward better overall healthcare in our country. Some tools that are commonly employed toward this goal are clinical practice guidelines and national administrative databases. The two methods are very dissimilar in their makeup and creation, but both can serve a common and shared purpose. This review provides the reader with an understanding of how our specialty can utilize these tools to improve healthcare.
\end{abstract}

Keywords Quality improvement - Administrative databases - Clinical practice guidelines - Maintenance of certification - National Surgical Quality Improvement Program (NSQIP) · Kids' Inpatient Database (KID)

M. E. McCormick

Department of Otolaryngology and Communication Sciences, Medical College of Wisconsin, Milwaukee, WI, USA

M. E. McCormick ( $₫)$

Division of Pediatric Otolaryngology, Children's Hospital of Wisconsin, 9000 W. Wisconsin Ave., Ste. 540, Milwaukee, WI 53226, USA

e-mail: mmccormick@mcw.edu

R. K. Shah

Division of Otolaryngology, Children's National Medical

Center, Washington, DC, USA

\section{Introduction}

There has been growing attention given to the efficiency of healthcare in the past decade, and this has led to a number of quality improvement movements and pieces of legislation aimed at healthcare reform. One of the main impetuses for this focus on quality is the increasing amount of healthcare spending in the USA, while our nation's performance in numerous metrics (e.g., life expectancy, obesity, infant mortality) continues to be among the lowest among industrialized countries. With the passage of the Patient Protection and Affordable Care Act (PPACA) of 2010 into law, the federal government has made it clear that quality healthcare is a national priority [1]. While debate exists among providers over what "quality" care is, the Agency for Healthcare Research and Quality (AHRQ) has defined it as "doing the right thing, at the right time, in the right way, for the right person-and having the best possible results" [2].

Rather than rely on a government official or agency to define "quality healthcare," medical societies and specialties such as otolaryngology are taking the opportunity and initiative to do so themselves. There are a number of ways a specialty can accomplish this task. One of the most common and effective methods is reviewing established evidence and practices and generating clinical practice guidelines, consensus statements, best practices, and clinical care pathways. Another way is to review large national administrative databases to identify trends in disease and management and establish benchmarks.

The purpose of this article is not to summarize existing literature and evidence, but rather to review the "why" and "how" behind these efforts. Our goal is to provide the reader with an understanding of the purpose of practice guidelines and the impact that administrative databases can 
Fig. 1 Clinical guidelines and databases are created based on current practices and established evidence. These tools are then utilized for quality improvement measures. This cycle continues as new evidence becomes available and is again reviewed and analyzed using the same methods

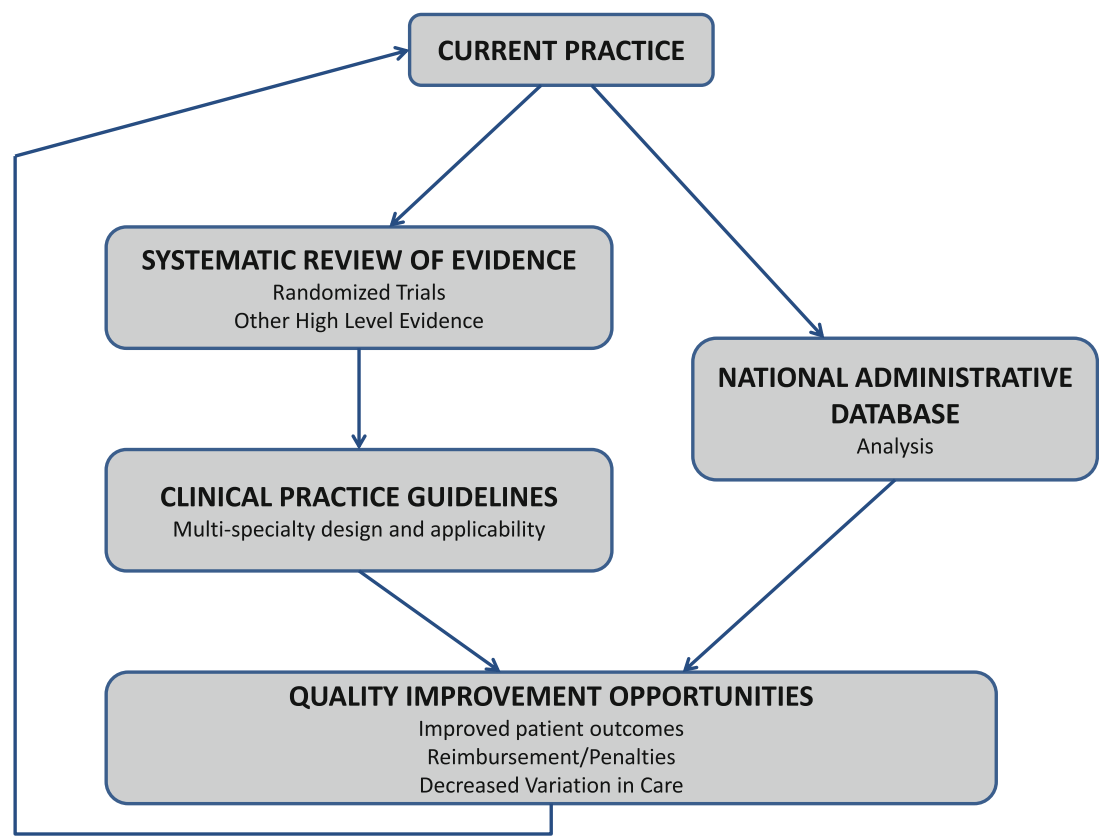

have on the establishment of quality in otolaryngology. Figure 1 presents a schematic overview of the guideline development process and incorporates how databases can be utilized for quality improvement in a parallel fashion.

\section{Clinical Practice Guidelines}

The Institute of Medicine (IOM) has identified the establishment of guidelines as one of three critical steps to creating an effective national healthcare system [3]. An effective clinical guideline examines the best available evidence on a topic and provides recommendations based on the quality of that evidence. In addition, guidelines are meant to be transparent and free of conflicts of interest and should be implementable by healthcare providers in multiple specialties $[4 \cdot \bullet$. The aim of this process is to promote best practices and to decrease variation and unnecessary healthcare spending.

This model assumes that high-quality evidence exists for the disease processes in question. As all physicians likely know, this is not always the case, and the absence of a "gold standard" for a particular question leads to an expected variation in practice. Surely this is how most medical breakthroughs in history have evolved-because variation led to a better answer than what currently existed. Critics of the process of "standardizing medicine" have cried that it will squelch innovation, but there is a large difference between inefficient practices and medical improvements. Clinical guidelines and other similar documents are not carved in stone, but are evolving themselves, incorporating new research and evidence into their foundations.
Table 1 Currently available clinical practice guidelines published by the AAO-HNS

\begin{tabular}{ll}
\hline Date & Clinical practice guideline (CPG) \\
\hline May 2004 & CPG: otitis media with effusion \\
April 2006 & CPG: acute otitis externa \\
September & CPG: adult sinusitis \\
2007 & \\
September & CPG: cerumen impaction \\
2008 & \\
November & CPG: benign paroxysmal positional vertigo \\
2008 & \\
September & CPG: hoarseness (dysphonia) \\
2009 & \\
January 2011 & CPG: tonsillectomy in children \\
July 2011 & CPG: polysomnography for sleep-disordered \\
March 2012 & CPG: sudden hearing loss \\
June 2013 & CPG: improving voice outcomes after thyroid surgery \\
July 2013 & CPG: tympanostomy tubes in children \\
\hline
\end{tabular}

Within the last decade, the American Academy of Otolaryngology-Head \& Neck Surgery (AAOHNS) has published 11 clinical practice guidelines (Table 1) [5-15]. In addition, the AAOHNS has also produced a number of clinical consensus statements on topics such as tracheostomy care and nasal valve compromise [16, 17]. Like guidelines, clinical consensus statements serve the goal of quality healthcare, but with a narrower scope, and the evidence is often of limited quality [18].

Adapting guidelines into clinical practice requires commitment and participation on a number of levels, including 
Table 2 Applicability of large-scale administrative databases

Population research
Demographics research
Disease prevalence, including geographic variation
Procedural variations
Monthly and seasonal variations
Resource utilization
Ancillary tests (laboratory tests, radiologic studies)
Prescription patterns
Charges ${ }^{\text {a }}$ for procedures and admissions
Regional/institutional variations
Measures of quality and efficiency
Length of stays and re-admission rates
Time-to-test (e.g., radiologic studies) and time-to-procedure
Clinical guideline adherence patterns

${ }^{a}$ Most databases provide the researcher with information on the

"charges" as opposed to "cost" of a procedure or admission

physicians, office managers, hospital administrators, and ancillary staff. Personnel must be educated in how the guidelines will affect their duties and incentives must be created. Through the Value-Based Purchasing (VBP) Program, The Centers of Medicare \& Medicaid Services (CMS) has begun to provide financial rewards to hospitals for compliance with meaningful use measures [e.g., electronic health record (EHR) maintenance and electronic prescribing (eRx)] [19]. Similarly, practice groups and hospitals can incentivize compliance with practice guidelines within their own institutions to improve participation [20••].

By following clinical practice guidelines and other quality-driven publications, otolaryngologists can align themselves with a larger movement toward efficient and effective healthcare. Participation can be further encouraged by both federal and institutional financial incentives.

\section{Utility of Administrative Databases}

Like guidelines, consensus statements, and other evidencebased measures, administrative databases can be utilized as a tool to make care more efficient and cost-effective. Highquality research on many disease processes is often not available, especially in rarer conditions and in at-risk populations (children, pregnant women) where randomized blinded studies are challenging to carry out. It is especially in these situations where large databases of aggregate data from around the nation can be useful.

Administrative databases can help to identify disease trends and establish benchmarks for treatment. They are particularly useful when an investigator is interested in the "cost" of care of a particular disease process as potential areas of unnecessary or avoidable resource expenditure can be identified [21, 22]. Table 2 provides an overview of the utility of administrative databases in quality and outcomes research.

There are a number of limitations to databases as research tools. They are large cross-sectional collections of data and rely on accurate coding on the parts of the participating healthcare providers. They allow a researcher to make broad observations about a disease process, but it is difficult to account for unique aspects of each patient/ admission and appropriately stratify risk. Individual patients cannot be followed longitudinally in most cases, and outcomes of treatments are often not available [21].

Overview of Commonly Used Administrative Databases

American College of Surgeons National Surgical Quality Improvement Program (ACS NSQIP)

Established in 1994 (initially) within the Veterans Affairs (VA) hospital system, the NSQIP employs a prospectivelyvalidated database to quantify 30 -day risk-adjusted surgical outcomes on a variety of disease processes [23, 24]. More than 100 publications have been published since its inception, ranging in topics from perioperative antibiotic use $[25,26]$. Within otolaryngology, important studies have emerged identifying risk factors for total laryngectomy and uvulopalatopharyngoplasty (UPPP) [27, 28].

The success of the ACS NSQIP within the VA system prompted expansion into the private sector and, with the help of the American Pediatric Surgical Association (APSA), eventually into the pediatric community. Beginning in 2008, the ACS NSQIP Pediatric (ACS NSQIP Peds) allows participating hospitals to collect and utilize data on surgical outcomes and to compare their performances with those of similar institutions. Otolaryngology was the first surgical specialty to initiate a pilot data collection examining surgical outcomes related to such pediatric procedures as tracheostomy, airway reconstruction, and neck abscesses [29].

\section{Healthcare Cost and Utilization Project (HCUP)}

Established by the AHRQ, the HCUP includes a variety of administrative databases including the Nationwide Inpatient Sample (NIS), the Kids' Inpatient Database (KID), and the Nationwide Emergency Department Sample (NEDS). These databases collect detailed data on hospital encounters around the country, and weighted data can be generated to allow estimates on a national basis. These tools are extremely useful for identifying longitudinal changes in disease management as well as regional variations in care. In addition, the AHRQ provides quality indicators (QIs) that make use of available administrative 
data and allow healthcare providers to identify potential quality concerns in their care and make appropriate investigations or changes [30].

\section{Pediatric Health Information System (PHIS)}

The PHIS contains data from 43 independent pediatric hospitals across North America and is organized and administered by the Children's Hospital Association (CHA). Included in this database are data from inpatient admissions, ambulatory surgeries, and emergency department visits. A notable advantage of PHIS is the use of patient identifiers to allow researchers to track care in a longitudinal fashion (i.e., across multiple hospital encounters). A potential utility of PHIS is the generation of "consensus" practices based on the experiences of participating pediatric specialists in situations where quality evidence is otherwise limited in the literature [31].

\section{Conclusion}

A good surgeon recognizes an effective tool when presented with it. Likewise, the otolaryngology community should continue our efforts in defining and refining our definitions of quality care. Clinical practice guidelines are the finished products of careful analysis of existing evidence and are intended to reduce variation and improve the efficiency and effectiveness of care. Administrative databases can be useful in evaluating surgical outcomes, providing evidence for rarer disease processes, and in analyzing variations in costs of healthcare. All of the tools reviewed in this article can serve a role in our mission to establish best practices, stimulate further investigations, and improve outcomes for our patients.

\section{Compliance with Ethics Guidelines}

Conflict of Interest Michael E. McCormick and Rahul K. Shah declare no conflicts of interest.

Human and Animal Rights and Informed Consent. This article does not contain any studies with human or animal subjects performed by the authors.

\section{References}

Papers of particular interest, published recently, have been highlighted as:

-• Of major importance

1. Pub. L No. 111-148, 124 Stat. 119 (2010), as amended by the Health Care and Education Reconcilitation Act of 2010, Pub. L. 111-152 (2010) (codified as amended in scattered titles of USC).
2. Agency for Healthcare Research \& Quality, United States Department of Health and Human Services. "Your guide to choosing quality health care" Books LLC, 2011. http://archive. ahrq.gov/consumer/qnt. Accessed 4 Sept 2013.

3. Eden JWB, McNeil B, Sox H. Institute of Medicine of the National Academies. Knowing what worlds in health care: a roadmap for the Nation. Washington, DC: National Academies Pres; 2008.

4. • Rosenfeld RM, Shiffman RN, Robertson P, Department of Otolaryngology State University of New York D. Clinical Practice Guideline Development Manual, Third Edition: a qualitydriven approach for translating evidence into action. Otolaryngology-head and neck surgery : official journal of American Academy of Otolaryngology-Head and Neck Surgery. Jan 2013;148(1 Suppl):S1-55.

5. Rosenfeld RM, Brown L, Cannon CR, et al. Clinical practice guideline: acute otitis externa. Otolaryngol Head Neck Surg. 2006;134(4 Suppl):S4-23.

6. Rosenfeld RM, Andes D, Bhattacharyya N, et al. Clinical practice guideline: adult sinusitis. Otolaryngol Head Neck Surg. 2007;137(3 Suppl):S1-31.

7. Bhattacharyya N, Baugh RF, Orvidas L, et al. Clinical practice guideline: benign paroxysmal positional vertigo. Otolaryngol Head Neck Surg. 2008;139(5 Suppl 4):S47-81.

8. Roland PS, Smith TL, Schwartz SR, et al. Clinical practice guideline: cerumen impaction. Otolaryngol Head Neck Surg. 2008;139(3 Suppl 2):S1-21.

9. Schwartz SR, Cohen SM, Dailey SH, et al. Clinical practice guideline: hoarseness (dysphonia). Otolaryngol Head Neck Surg. 2009;141(3 Suppl 2):S1-31.

10. Chandrasekhar SS, Randolph GW, Seidman MD, et al. Clinical practice guideline: improving voice outcomes after thyroid surgery. Otolaryngol Head Neck Surg. 2013;148(6 Suppl):S1-37.

11. Rosenfeld RM, Culpepper L, Doyle KJ, et al. Clinical practice guideline: otitis media with effusion. Otolaryngol Head Neck Surg. 2004;130(5 Suppl):S95-118.

12. Roland PS, Rosenfeld RM, Brooks LJ, et al. Clinical practice guideline: polysomnography for sleep-disordered breathing prior to tonsillectomy in children. Otolaryngol Head Neck Surg. 2011;145(1 Suppl):S1-15.

13. Stachler RJ, Chandrasekhar SS, Archer SM, et al. Clinical practice guideline: sudden hearing loss. Otolaryngol Head Neck Surg. 2012;146(3 Suppl):S1-35.

14. Baugh RF, Archer SM, Mitchell RB, et al. Clinical practice guideline: tonsillectomy in children. Otolaryngol Head Neck Surg. 2011;144(1 Suppl):S1-30.

15. Rosenfeld RM, Schwartz SR, Pynnonen MA, et al. Clinical practice guideline: tympanostomy tubes in children. Otolaryngol Head Neck Surg. 2013;149(1 Suppl):S1-35.

16. Mitchell RB, Hussey HM, Setzen G, et al. Clinical consensus statement: tracheostomy care. Otolaryngol Head Neck Surg. 2013;148(1):6-20.

17. Rhee JSWE, Park SS, et al. Clinical consensus statement: diagnosis and management of nasal valve compromise. YMHN. 2010;143(1):48-59.

18. American Academy of Otolaryngology-Head \& Neck Surgery Clinical Consensus Statement Manual. http://www.entnet.org/ Practice/upload/Clinical-Consensus-Statement_June08-2.pdf. Accessed 28 May 2013.

19. Centers for Medicare \& Medicaid Services. "Hospital ValueBased Purchasing Programs" http://www.cms.gov/Outreach-andEducation/Medicare-Learning-Network-MLN/MLNProducts/ downloads/Hospital_VBPurchasing_Fact_Sheet_ICN907664.pdf. Accessed 7 Sept 2013.

20. $\bullet$ Ishii LE. Closing the clinical gap: translating best practice knowledge to performance with guidelines implementation. 
Otolaryngology-head and neck surgery : official journal of American Academy of Otolaryngology-Head and Neck Surgery. Jun 2013;148(6):898-901. (Good blueprint of how an institution or individual can incorporate guidelines into their daily practice).

21. Boss EF, Shah RK. An overview of administrative and national survey databases for use in otolaryngology research. Otolaryngol Head Neck Surg. 2013;148(5):711-6.

22. Shah RK. Unlocking the value in administrative databases. Laryngoscope. 2012;122(Suppl 4):S65-6.

23. Itani KM. Fifteen years of the National Surgical Quality Improvement Program in review. Am J Surg. 2009;198(5 Suppl):S9-18.

24. Khuri SF. Safety, quality, and the National Surgical Quality Improvement Program. The American surgeon. 2006;72(11):994-8 discussion 1021-1030, 1133-1048.

25. Hawn MT, Gray SH, Vick CC, et al. Timely administration of prophylactic antibiotics for major surgical procedures. J Am Coll Surg. 2006;203(6):803-11.

26. Rogers SO Jr, Kilaru RK, Hosokawa P, Henderson WG, Zinner MJ, Khuri SF. Multivariable predictors of postoperative venous thromboembolic events after general and vascular surgery: results from the patient safety in surgery study. J Am Coll Surg. 2007;204(6):1211-21.

27. Kezirian EJ, Weaver EM, Yueh B, Khuri SF, Daley J, Henderson WG. Risk factors for serious complication after uvulopalatopharyngoplasty. Arch Otolaryngol Head Neck Surg. 2006;132(10):1091-8.

28. Schwartz SR, Yueh B, Maynard C, Daley J, Henderson W, Khuri SF. Predictors of wound complications after laryngectomy: a study of over 2000 patients. Otolaryngol Head Neck Surg. 2004;131(1):61-8.

29. American College of Surgeons. National Surgical Quality Improvement Program Pediatric; Chicago: ACS NSQIP Pediatric Semiannual Report, January 1, 2012, December 31, 2012.

30. Agency for Healthcare Research and Quality RMD. HCUP Overview. Healthcare Cost and Utilization Project (HCUP). Rockville, MD: Agency for Healthcare Research and Quality; 2009. http://www.hcup-us.ahrq.gov/overview.jsp. Accessed 7 Sept 2013.

31. Kittle K, Currier K, Dyk L, Newman K. Using a pediatric database to drive quality improvement. Semin Pediatr Surg. 2002;11(1):60-3. 